\title{
Una ventana a la intimidad: los muebles de cama y de sala en el espacio doméstico de Pachuca, siglo XVII
}

A window to privacy: bed and living room furniture in the domestic space of Pachuca, XVII century

Carmen Lorenzo-Monterrubio ${ }^{a}$

\begin{abstract}
:
The intimate and the private are aspects that unfortunately little are known in the history of daily life, however, we can access this information through the study of inventories of goods (like dowry cards), which number furniture that were intended for the domestic sphere such as bedrooms and rooms, considered mostly as luxury pieces obtained through overseas trade. In this article we will made special reference to beds, screens, skirting boards and mirrors, which were also symbols of status and prestige in a space dominated basically by women.
\end{abstract}

Keywords:

Endowment, furniture, domestic space, women, Pachuca

Resumen:

Lo íntimo y lo privado son aspectos que por desgracia poco se conocen en la historia de la vida cotidiana, sin embargo, podemos acceder a esta información a través del estudio de inventarios de bienes (como las cartas de dote), que numeran muebles que se destinaban al ámbito doméstico como las recámaras y las salas, considerados en su mayoría como piezas de lujo obtenidos a través del comercio ultramarino. En este artículo haremos referencia especial a las camas, los biombos, los rodaestrados y los espejos, que constituyeron además símbolos de estatus y prestigio en un espacio dominado básicamente por mujeres.

\section{Palabras Clave:}

Dotes, muebles, espacio doméstico, mujeres, Pachuca

\section{Introducción}

El estudio de la vida privada es importante para reconocer la historia íntima de las familias y cómo actuaban en el ámbito doméstico. Entre los documentos que nos permiten adentrarnos a este espacio se encuentran los inventarios de bienes (como son las cartas de dote), que nos muestran los bienes que se encontraban al interior de los hogares, que no solo se usaban sino también se exhibían y se presumían. En este sentido, los muebles nos permiten no solo reconocer la situación económica y política de sus dueños, sino también sus aspiraciones y cómo se desenvolvían en su vida privada.

A través de los objetos muebles e inmuebles que se observan al interior de los hogares tenemos también un referente femenino, al ser lo doméstico un sitio exclusivo para las mujeres, dado que les estaba vedado el espacio público.

En este artículo haremos una revisión de los muebles de cama y de sala (camas, biombos, rodaestrados y espejos) que se mencionan en las cartas de dote de Pachuca del siglo XVII (Lorenzo, 2015), considerando sus implicaciones sociales, económicas y simbólicas.

\section{Desarrollo \\ El Real y Minas de Pachuca}

A principios del siglo XVII, a Pachuca se le anteponía el nombre de Real y Minas (antiguamente Tlahuelilpa), cuyo origen fue el de un pueblo de españoles mineros. De acuerdo con la "Anónima Descripción de las Minas de Pachuca", el Real de Tlahuelilpa se localizaba entre cerros, "en las quebradas de ellas y en lo más llano, y es

Autor de Correspondencia, Universidad Autónoma del Estado de Hidalgo, https://orcid.org/0000-0002-0906-0531, Email: alorenzo@uaeh.edu.mx 
lo mucho el sitio de este real que entran los carros hasta las puertas de las casas dél" (Menes, 1993:42).

En ese entonces, Pachuca estaba la jurisdicción de la ciudad de México y no contaba con un escudo de armas "ni privilegio ni merced particular de Su Majestad" (Menes, 1993:43). Existían alrededor de doscientas casas, bajas, con paredes de adobe y techos de terrado y tejamanil, apartadas "como a tiro de arcabuz" (Menes, 1993:43).

El Real y Minas de Pachuca era, entonces, un poblado pequeño que contaba con una calle por donde pasaban las procesiones, un camino real que iba a la ciudad de México, un arroyo principal, carnicerías y plazas. La mayoría de las construcciones de Pachuca eran casas de vivienda, que se diferenciaban unas de otras por su tamaño y calidad. Las de las familias más ricas tenían varios cuartos o aposentos y su construcción era de materiales más fuertes, mientras que las más modestas eran pequeñas y de materiales perecederos.

Es así que entre las familias de estrato social medio o medio alto de Pachuca existían diferencias, de los más favorecidos económica y políticamente como los Rivadeneira y los Luzón y Ahumada, y los poco menos privilegiados como los Soto y los Montenegro. Hay que destacar que estas familias compartían el gusto por los objetos importados, especialmente de China, España y Francia, es así que en estos hogares abundaban terciopelos, brocados, porcelanas, telas y muebles, entre otros. La diferencia radicaba en que en las familias con menos recursos los objetos que poseían eran más modestos o de menor valor que los de las familias más favorecidas. Se podría esperar que en esta y otras sociedades, en los primeros grupos la mayor cantidad de estos objetos fueran usados, "viejos" o "a medio servir", mientras que en los últimos grupos fueran, en mayor medida, nuevos; sin embargo, en realidad sucedió lo contrario, los primeros tenían mayor cantidad de objetos nuevos.

\section{Los documentos dotales}

Pilar Gonzalbo define la dote como la aportación de la familia de la mujer al matrimonio, con el fin de "ayudar a sustentar las cargas del matrimonio" (1996:207), y cuya entrega se hacía ante un escribano público. La dote era una forma de ayuda "a las cargas del matrimonio" o de "sustento de las cargas del matrimonio" (Lavrín, 1985:48), y el marido fungía como administrador de los bienes que se le entregaban, quien en teoría los usaba para invertirlos o incrementarlos.

Es relevante el papel que jugó la mujer en el desarrollo social y económico de Pachuca durante el siglo XVII, ya que a través de los bienes dotales se tejió un entramado de poder y de prestigio por medio de vínculos matrimoniales, además se promovió el flujo comercial interior y exterior de bienes de lujo que, como los muebles, llegaron a exhibirse y presumirse en los espacios domésticos.

Las cartas de dote reflejan la búsqueda por obtener riqueza y poder, o bien, permanecer en una posición social privilegiada. Las alianzas matrimoniales sirvieron para reforzar vínculos de poder y además, como sucedió en Pachuca, establecer asociaciones entre ricos mineros y comerciantes para acrecentar sus fortunas y extender su influencia a otras ramas de la economía como la ganadería.

Los bienes dotales variaban según la condición socioeconómica de la familia y generalmente consistían en enseres domésticos y ropa, además de esclavos, dinero y propiedades en el mejor de los casos. Las dotes más codiciadas fueron aquellas que incluían propiedades o dinero, ya que el marido podía usarlos como capital para su inversión y obtener ganancias. A pesar de que durante el siglo XVII se dotaron en Pachuca algunas propiedades importantes como haciendas y minas, además de dinero y plata, la mayoría de las dotes consistían en vestidos y muebles, que "no se consideraban como una base de la consolidación de la riqueza" (Lavrín, 1985:49), sin embargo, si lo eran para promover un mejor estatus social.

Los ajuares domésticos dan cuenta no sólo de las posesiones, también de la cotidianeidad dentro del seno familiar, de las formas de vestir, de comer y de lucir. La sociedad novohispana basaba su prestigio en los bienes que poseía, así, la aristocracia gozaba de una posición privilegiada de acuerdo a la posesión de "esclavos y sirvientes, carruajes y palanquines, ropa suntuosa, joyas y objetos de lujo" (Rubial, 1994:78).

De acuerdo a Pilar Gonzalbo, el simbolismo dado a los bienes dotales determinaba la formalización de una relación (2007:1143). De acuerdo con la misma autora, la condición de la vivienda, las características del vestuario y los bienes suntuarios estaba definida por la posición social del grupo (1992:361-365). La cultura material posee características que permiten reconocer los valores sociales, es así que en la sociedad de Pachuca del siglo XVII el exhibir ostentosos vestidos y rica joyería, vivir en un escenario de lujo y poseer muebles costosos como camas, biombos, rodaestrados y espejos, fue símbolo de estatus y de prestigio.

En sí, la exhibición de las fortunas daba a las familias reconocimiento social. En realidad se buscaba pertenecer o por lo menos pretender ser iguales a los españoles y nobles, y se mostraban las posesiones y lujos cada vez que se podía en reuniones, comidas y festejos, con el fin de lograr posición y aceptación en la sociedad (Brading, 1985:41). El lucimiento de ricas telas, portar finas joyas, ofrecer el asiento en muebles importados, presentar la comida en vajillas de porcelana chinas, pisar preciosas alfombras y hacer público los sirvientes y esclavos de la casa, traía consigo prestigio y reconocimiento social. El hombre del Virreinato "cifró en la adquisición y acumulación de bienes suntuarios su poderío económico y prestigio social. Por medio de la posesión de [...] multitud de ricos objetos, las clases más privilegiadas de la sociedad manifestaron al resto de la población, tanto los valores de la cultura occidental como los medios de comportamiento a seguir" (Curiel, 1992:128).

El estudio de los muebles que fueron dados en dote en Pachuca en el siglo XVII nos da una visión no sólo de las diferencias dentro de la sociedad, sino también de cómo los grupos sociales definían su nivel de estatus y privilegios. Para la sociedad de Pachuca 
era fundamental conquistar el poder político y ascender altos niveles de la jerarquía social (Cubillo, 1991:277), que se lograba con la adquisición de bienes de lujo que provenían del exterior. Es así que aunado a la minería se consolidó el comercio, y los comerciantes o mercaderes llegaron a ser un poderoso sector en la economía local.

Muchos de los objetos que encontramos en los ajuares domésticos de Pachuca del siglo XVII fueron adquiridos a través de un comercio regional y local, pero sobre todo ultramarino. Es así que Gustavo Curiel establece un carácter tripartita en cuanto al origen de los objetos, es decir, aquellos traídos a través el comercio exterior, los que llegaron del interior del país y los que se producían localmente, llamados "de la tierra" o "de la sierra" (Curiel, 1992), por lo que encontramos conviviendo en un mismo espacio camas y colchones provenientes de China, así como de Michoacán, Chiapas y Xochimilco.

Incluso en los inventarios de bienes más pobres aparecen objetos de importación, "lo que indica que las piezas suntuarias no sólo llegaron a ser adquiridas por las clases más acomodadas del virreinato" (Curiel, 1992:141), aunque claro, los precios variaban según la calidad del producto. Una particularidad de los ajuares domésticos de Pachuca del siglo XVII es la presencia de muebles de cama y de sala en los estratos medios y altos de la sociedad.

\section{Los muebles de cama y de sala}

Nueva España efectuó por el Atlántico un comercio con la metrópoli española y también con Cuba y Venezuela, a través del puerto de Veracruz. Mientras que por el Pacífico el principal flujo comercial se dio entre Acapulco y Filipinas, y por esta vía se traficó también con Guatemala y Perú.

Con la apertura de nuevas rutas marítimas de comercio, el llamado Galeón de Manila logró llevar cada año al puerto de Acapulco objetos de China, Japón y Manila. El gusto por los objetos orientales se arraigó sobre todo en las familias adineradas de la sociedad novohispana, adquiriendo para sus casas muebles como biombos y rodaestrados, además de porcelanas, textiles, pinturas y otros.

A la vez, con el surgimiento de los centros mineros como Pachuca se fueron desarrollando a su alrededor espacios económicos integrados y especializados que abastecían de productos y alimentos a la creciente y demandante población, es decir, que la explotación de la plata facilitó la creación de centros de producción en diferentes ramos, ajenos a su función original (Pérez, 1992:81).

En un inicio, Pachuca se fundó como centro minero para después incorporar a sitios de producción encargados del abastecimiento de recursos, a través de actividades agropecuarias. Su desarrollo estuvo ligado al crecimiento de un área de influencia que incorporaba una vasta región y le proporcionaba un abasto seguro (Mijares, 2005:123).

\footnotetext{
* Peribán es una localidad de Michoacán donde se fabricaban lacas.
}

Debemos considerar también que Pachuca fue, desde sus inicios, un punto estratégico comercial donde confluían diversos productos que iban a la costa del Golfo, al altiplano o a diversas regiones o comunidades del norte. Una vez establecidas las haciendas mineras y los ingenios de moler metales, se fue creando una red de comercio regional para la provisión de la creciente población española y del resto de la población indígena.

La mayor parte del territorio novohispano contaba, en el mejor de los casos, con caminos de herradura y veredas donde circulaban bestias de carga. El trayecto era pesado, lento y costoso, además las condiciones de los caminos no eran buenas, sobre todo en tiempo de lluvias. De aquí que el viaje terrestre no fuera redituable, y sólo se realizaba en la medida que los productos eran de muy alto valor y no se echaran a perder, como fue el caso de los muebles (Mijares, 2005:128-130).

A continuación haremos una breve descripción de camas, biombos, rodaestrados y espejos, que constituyeron un símbolo de prestigio, ya que eran objetos sumamente caros, obtenidos a través del comercio exterior e interior.

En el siglo XVII novohispano existieron varios tipos de camas: con una o dos cabeceras, altas, bajas, camas enteras o medias camas, y de diferentes clases de madera. Su valor dependía entonces de su calidad y tamaño. De acuerdo con la madera, existían aquellas hechas de maderas finas como el granadillo y tapinsirán, y de las más costosas podemos citar las de madera laqueada con fondo rojo o negro traídas de China y las de ébano con columnas salomónicas e incrustaciones de marfil. El cedro se empleó también para la fabricación de muebles, aunque fue una de las maderas más baratas. Las camas más modestas, como las producidas con madera ordinaria (de pino) de Xochimilco, se destinaban a la servidumbre (Curiel, 2005:98). Para su fabricación, se usaron también molduras de bronce dorado, embutidos y lacas de peribán *. En Pachuca, una cama de camino con cielo de damasco, con su cobertor y goteras de terciopelo, que se metía en un cofre para poder llevarse en los viajes, fue valuada en cuatrocientos pesos, y fue de lo más caro de los bienes en el año $1604^{\dagger}$. Los colchones, a su vez, se rellenaban de lana y algunos provenían de China. Había colchones cameros que eran los más grandes y medios cameros, los más pequeños. Las colgaduras de cama se sostenían por cuatro pilares que se encontraban en las esquinas de las camas, que podían ser de varios tipos de telas, algunas de importación. Como veremos, en las recámaras también se colocaban los biombos de cama. Otros objetos que se encontraban en estos espacios eran baúles o cajas en los que se guardaba la ropa, ya que los roperos y las cómodas hicieron su aparición hasta el siglo XVIII (Curiel, 2005:100).

En cuanto a los accesorios de cama, no existe mucha variación entre los diferentes estratos sociales, encontramos almohadas, acericos (pequeñas almohadas), colchas de seda de China y sábanas. Las almohadas se apilaban hasta tres para descansar o

\footnotetext{
${ }^{\dagger}$ AHPJEH. Pachuca Protocolos. Escribano Juan Núñez Morquecho. Clasificación: EN. 33, NC. 12, NP. 170, C. 22, 1604, f. 2r.
} 
dormir. Otros componentes del ajuar de cama eran los rodapiés y los traveseros, "piezas que por lo general hacían juego con las sobrecamas, colchas, los cortinajes y los doseles" (Curiel, 2005:99).

Entre los muebles de sala y de cama destacan los rodaestrados y los biombos. Los primeros eran biombos pequeños que se ubicaban en el estrado o la sala de visitas, aunque en las recámaras había biombos más grandes, que eran los llamados biombos de cama. Debido al intenso tráfico comercial con los países orientales, los biombos llegaron a revolucionar los muebles que existían en la Nueva España en el siglo XVII. Cobraron importancia en casas y palacios, y servían de protección contra el viento y el frío, además de ofrecer intimidad (Martínez, 1982:1169). "Si bien estos muebles orientales arribaron a las casas de los ricos en el último tercio del siglo XVI, fue en la siguiente centuria cuando proliferaron, tanto los de importación como los hechos en Nueva España" (Curiel, 2005:85). Los biombos se pintaban de uno o ambos lados y podían ser de laca de china, pintura al óleo, o bien, de tela los más modestos.

Con relación a los espejos, se consideraban parte importante en el menaje de las casas. Algunos eran sumamente caros, sobre todo si estaban enmarcados en plata labrada, ébano, marfil, maque oriental, carey o fina marquetería. "Estas piezas símbolos por excelencia de la vanidad humana- se convirtieron en distintivos sociales (toda familia de importancia debía tener espejos en sus casas)" (Curiel, 2005:87). Fueron pocos los espejos que había en Pachuca del siglo XVII, y hay que destacar su presencia en el menaje de familias menos afortunadas.

Para facilitar la clasificación de estos objetos y su distribución en la sociedad de Pachuca del siglo XVII, se agruparon en seis categorías, dependiendo de las cantidades dadas en dote, desde las más modestas hasta las más ricas.

\section{Primer grupo (200 - 1,000 pesos)}

En el primer grupo, el de las dotes entre doscientos y mil pesos, encontramos una de las camas más caras dadas en dote en Pachuca, en cien pesos, además, otras camas de granadillo y de madera ordinaria, armaduras de cama torneadas y un armazón de media cama de madera ordinaria. Sorprende también la existencia en este grupo de dos espejos, uno de cristal grande y otro nuevo.

- camas: cama dorada con una colgadura de lienzo de China (100 pesos), de madera ordinaria, dorada, "de

\footnotetext{
* AHPJEH. Pachuca Protocolos. Escribano Fernando de Contreras. Clasificación:EN. 47, NC. 19, C. 39, NP. 269, 1676.

† AHPJEH. Pachuca Protocolos. Escribano Juan de Terán. Clasificación: EN. 42, NC. 14, C. 31, NP. 237, 1637.

‡ AHPJEH. Pachuca Protocolos. Escribano Fernando de Contreras.

Clasificación: EN. 47, NC. 19, C. 39, NP. 269, 1676.

$\S$ AHPJEH. Pachuca Protocolos. Escribano Juan de Terán. Clasificación: EN. 42, NC. 14, C. 31, NP. 237, 1637.

** AHPJEH. Pachuca Protocolos. Escribano Juan de Terán. Clasificación: EN. 42, NC. 14, C. 31 , NP. $237,1637$.

${ }^{\dagger}$ AHPJEH. Pachuca Protocolos. Escribano Fernando de Contreras. Clasificación: EN. 47, NC. 10, C. 37, NP. 260, 1669.

林 AHPJEH. Pachuca Protocolos. Escribano Fernando de Contreras.

Clasificación: EN. 47, NC. 29, C. 40, NP. 279, 1688.
}

granadillo con molduras de bronce dorado (35 pesos)" ${ }^{n *}$, de granadillo.

- armadura de cama: "de madera torneada de México (5 pesos)"

- armazón de media cama: de madera ordinaria.

- colchones: camero de brin con su lana, de lienzo, de lana, de cotense, de vara.

- espejos: "de cristal grande (7 pesos)" $\ddagger$, "nuevo (4 pesos)"§.

\section{Segundo grupo $(1,000-2,000$ pesos $)$}

En el grupo con dotes entre mil y dos mil pesos es mayor la cantidad de muebles. Aparecen varias camas, una proveniente de China, otra de Michoacán y, el resto, hechas generalmente de granadillo. Algunos colchones fueron traídos también de China, que se rellenaban de lana. Encontramos en este grupo un espejo grande con marco dorado.

- camas: "cama de China labrada (10 pesos)"** "entera de granadillo con molduras de bronce (50 pesos)" "†, "de granadillo con su pabellón de damasco azul y manga (80 pesos)" $" \neq$, de madera, de madera ordinaria, de madera dorada, media cama dorada, tornada, "media cama de granadillo guarnecida de bronce dorado (50 pesos)"§§, "una cama de granadillo guarnecida de bronce (34 pesos)" ",*** de granadillo, con colgadura y rodapiés, cama de Michoacán (6 pesos).

- colchones: cameros, de brin, de petatillo, de cotense, de crea vetada, con su lana, llenos de lana, grande y pequeño, de hilaza, de China, colchón de China de lana (6 pesos). - espejo: "un espejo de cristal grande con su marco dorado (5 pesos y 4 reales)" $"+t$.

\section{Tercer grupo (2,000 - 4,000 pesos)}

El grupo con dotes entre dos y cuatro mil pesos es quizá el que tiene una mayor cantidad de muebles, sobre todo camas, colgaduras de cama y colchones. Aparece un biombo pintado. Dos espejos de cristal presentan marcos, uno de ébano y otro con molduras doradas. - camas: de granadillo, de madera, de madera de granadillo, de madera de Michoacán, blanca torneada, de madera granadina, "una cama de granadillo nueva con molduras y manzanillas de bronce dorado (45 pesos)" $¥ \neq \ddagger$, con guarniciones de bronce dorado, bordada de seda (colorada), con molduras de bronce, "una cama de madera baja dorada (20 pesos)"§§§, dorada, con sus cortinas de paño, bronceada, con colgadura, con varas de hierro, con los extremos de bronce dorado, con dos colchones, "una cama de madera en cien pesos por ser alta"****, cama de granadillo bronceada con su colgadura blanca de red de Campeche y sus barras de hierro (60 pesos), media cama de granadillo con molduras de bronce.

\footnotetext{
$\S$ AHPJEH. Pachuca Protocolos. Escribano Fernando de Contreras. Clasificación: EN. 47, NC. 7. C. 36, NP. 257, 1667.

*** AHPJEH. Pachuca Protocolos. Escribano Juan de Solís y Alcázar. Clasificación: EN. 50, NC. 3, C. 42, NP. 291, 1690.

ti个 AHPJEH. Pachuca Protocolos. Escribano Fernando de Contreras. Clasificación: EN. 47, NC. 19, C. 39, NP. 269, 1676

\$+ AHPJEH. Pachuca Protocolos. Escribano Fernando de Contreras Clasificación: EN. 47, NC. 20, C. 39, NP. 270, 1637.

$\S \S \S$ AHPJEH. Pachuca Protocolos. Escribano Juan de Terán. Clasificación EN. 42, NC. 14, C. 31, NP. 237, 1637.

${ }^{* * * *}$ AHPJEH. Pachuca Protocolos. Escribano Juan de Terán. Clasificación: EN. 42 , NC. 23 , C. 34 , NP. $246,1649$.
} 
- colgaduras de cama: "una colgadura de cama de Damasco carmesí con su colcha encarnada bien tratada apreciada en cien pesos", "una colgadura de cama de Damasco carmesí con su colcha encarnada bien tratada (8 pesos)" ${ }^{\circ}$, de China, "una colgadura de cama de damasco azul mandarín de China con su cielo y [...] de terciopelo carmesí con cinco cortinas (110 pesos)" $¥$, "una colgadura de rey de China para la dicha cama (18 pesos)"§, blanca de red de Campeche, "una colgadura de cama de chitas finas de China guarnecidas de listón verde con sus varillas de hierro (25 pesos)"

- colchones: de cotense, camero, con su lana, lleno de lana, de brin, de chapaneco, dos colchones cameros de chapaneco llenos de lana (20 pesos), dos colchones nuevos de chapaneco llenos de lana ( 25 pesos)

- biombo: pintado.

- espejos: "un espejo de cristal con marco de ébano (10 pesos)" "†', con su marco dorado de molduras, "un espejo grande de cristal guarnecido con sus molduras doradas (10 pesos)"

\section{Cuarto grupo (4,000 - 6,000 pesos)}

En el siguiente grupo con dotes entre cuatro y seis mil pesos disminuyen los muebles de cama y de sala. Encontramos dos biombos, uno de estrado y otro de cama, además un espejo grande.

- camas: "una cama de madera de granadillo entera con molduras de bronce dorado (50 pesos)"§§, de granadillo, abronsada, "una cama entera dorada con colgaduras de grana y una sobrecama de damasco verde con cenefa carmesí y oro (250 pesos)" "***, "una cama de granadillo con su colgadura de seda (100 pesos)"ttt.

- media cama: "una media cama de granadillo con remate de bronce (40 pesos)" "łł .

- colgaduras de cama: de damasco, con cortinas de capichola (encarnada), de damasco carmesí enredado y peinecillo y con sus cortinas de capichola encarnada apreciado todo en (100 pesos)

- colchones: de cotense, de cotense florete, llenos de lana, con su lana, de brin, cameros.

- biombo de estrado: "un biombo de estrado nuevo (80 pesos)"§§§.

- biombo de cama: "otro biombo de cama" (25 pesos)",****

- espejo: "un espejo de media vara de largo con su luna de cristal y marco de ébano (24 pesos)" "†t+, grande.

\section{Quinto grupo (6,000 - más de 7,000 pesos)}

\footnotetext{
*AHPJEH. Pachuca Protocolos. Escribano Fernando de Contreras. Clasificación: EN. 47, NC. 22, C. 39, NP. 272, 1679.

${ }^{\dagger}$ AHPJEH. Pachuca Protocolos. Escribano Fernando de Contreras. Clasificación: EN. 47, NC. 22, C. 39, NP. 272, 1679.

${ }^{\ddagger}$ AHPJEH. Pachuca Protocolos. Escribano Fernando de Contreras. Clasificación: EN. 47, NC. 19, C. 39, NP. 269, 1676.

$\S$ AHPJEH. Pachuca Protocolos. Escribano Juan Núñez Morquecho. Clasificación: EN. 33, NC. 20, C. 23, NP. 178, 1606.

** AHPJEH. Pachuca Protocolos. Escribano José de Ulloa y Callejas. Clasificación: EN. 52, NC. 5, C. 45, NP. 313, 1693.

\# AHPJEH. Pachuca Protocolos. Escribano Fernando de Contreras. Clasificación: EN. 47, NC. 22, C. 39, NP. 272, 1679.

林 AHPJEH. Pachuca Protocolos. Escribano Juan de Terán. Clasificación: EN. 42, NC. 23, C. 34, NP. 246, 1649.

$\$$ AHPJEH. Pachuca Protocolos. Escribano Fernando de Contreras.

Clasificación: EN. 47, NC. 24, C. 40, NP. 274, 1683.

${ }^{* * *}$ AHPJEH. Pachuca Protocolos. Escribano Juan de Terán. Clasificación: EN. 42, NC. 19, C. 33, NP. 242, 1643.

\#†ं AHPJEH. Pachuca Protocolos. Escribano Juan de Avendaño.

Clasificación: EN. 53, NC. 3, C. 45, NP. 317, 1696.
}

El grupo con dotes de seis a siete mil pesos presenta menor cantidad de muebles de cama y de sala, respecto a los anteriores. Una cama de doscientos treinta pesos y un rodaestrado de raso de China con alfombra y cojines en ciento cincuenta pesos, llegan a ser lo más caro en este grupo.

- camas: "una cama de campo de tafetán doble carmesí con sus alamares de oro y seda y flecos de lo mismo con su sobrecama (230 pesos)"łłł‡, "una cama de tapinsirán con colgadura de saya rosada con dos colchones de terlis llenos de lana (150 pesos)"§§§§, de granadillo, con molduras de bronce dorado, bronceada, Ilana.

- media cama: de granadillo, con molduras de bronce dorado.

- colchones: de León, con su lana, con su lana adentro, llenos de lana, de cotense, cameros (azules).

- un rodaestrado de raso de China verde y una alfombra y doce cojines de raso azul y encarnado (150 pesos).

\section{Sexto grupo (las más cuantiosas)}

En el último grupo, el de las dotes más altas, son cada vez más escasos los muebles, aunque observamos un conjunto de cama de cuatrocientos pesos, el más caro con relación a las demás camas de los otros grupos.

También observamos una colgadura de cama de Castilla, unos colchones cameros y un espejo que se valuó, según su tamaño, en dos pesos.

- camas: "con sus óvalos de bronce y colgadura de damasco maltratada (30 pesos)" ${ }^{\text {} \star \star \star \star \star}$, de madera blanca, torneada de Xochimilco, cama torneada de Xochimilco (12 reales), "una cama de camino con [...] cielo de damasco verde con su cobertor y goteras de terciopelo verde en un cofre todo (400 pesos)"t+t+†.

- colgadura de cama: "una colgadura de cama de tafetán carmesí de Castilla y una colcha de Holanda blanca (120

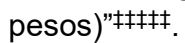

- colchones: cameros.

- espejo: "un espejo número diez (2 pesos)"§§§§§.

Como vemos en esta relación, existió una gran diversidad de muebles de cama y de sala al interior de los ajuares domésticos de Pachuca durante el siglo XVII. Los espacios de sala y de recámara, con seguridad, fueron los que más frecuentaban las mujeres, ya que los primeros se destinaban al esparcimiento y a la atención de las visitas, mientras que los segundos funcionaban

\#+ AHPJEH. Pachuca Protocolos. Escribano Fernando de Contreras Clasificación: EN. 47, NC. 15, C. 38, NP. 265, 1672.

$\S \S \S$ AHPJEH. Pachuca Protocolos. Escribano Juan de Avendaño. Clasificación: EN. 53, NC. 3, C. 45, NP. 317, 1696.

AHPJEH. Pachuca Protocolos. Escribano Juan de Avendaño. Clasificación: EN. 53, NC. 3, C. 45, NP. 317, 1696.

†ों AHPJEH. Pachuca Protocolos. Escribano Fernando de Contreras. Clasificación: EN. 47, NC. 24, C. 40, NP. 274, 1683.

林 AHPJEH. Pachuca Protocolos. Escribano Juan de Terán. Clasificación: EN. 42, NC. 17, C. 32, NP. 240, 1641.

$\S \S \S$ AHPJEH. Pachuca Protocolos. Escribano Fernando de Contreras. Clasificación: EN. 47, NC. 10, C. 37, NP. 260, 1669.

AHPJEH. Pachuca Protocolos. Escribano Juan de Solís y Alcázar. Clasificación: EN. 50, NC. 4, C. 42, NP. 292, 1691.

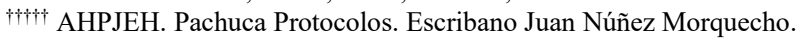
Clasificación: EN. 38, NC. 12, C. 22, NP. 170, 1604.

林林 AHPJEH. Pachuca Protocolos. Escribano Juan de Terán. Clasificación: EN. 42, NC. 8, C. 29, NP. 231, 1633.

$\S \S \$ \S \S$ AHPJEH. Pachuca Protocolos. Escribano Juan de Solís y Alcázar. Clasificación: EN. 50, NC. 4, C. 42, NP. 292, 1691. 
para la contemplación y el descanso. Recordemos que las familias pudientes contaban con esclavas (también dadas en dote) que se encargaban de las labores cotidianas domésticas.

\section{Conclusiones}

A partir del estudio de la dote matrimonial y de las cartas de dote (como inventarios de bienes), podemos acceder a una información que es poco conocida en la historia de la vida cotidiana: lo íntimo y lo privado en el ámbito doméstico. Así, los bienes que fueron dotados durante el siglo XVII en Pachuca nos permiten reconocer los valores y las aspiraciones de los diferentes grupos, tanto de la élite como de estratos medios y medios altos de la sociedad.

Algunos objetos tuvieron especial significado para promover o reforzar el estatus social de sus dueños, tal es el caso de los muebles de cama y de sala. Era un lujo poseer camas de maderas finas, rodaestrados y biombos traídos de China, además de espejos, que fueron excepcionales.

En una sociedad de apariencias, era necesario ofrecer una imagen de lujo y opulencia, es así que no solo las familias más favorecidas, sino también aquellas que contaban con menos recursos económicos, basaran su prestigio y estatus social en la cantidad y calidad de los bienes que poseían, sobre todo si eran de importación, como lo fueron los muebles. El extenso tráfico comercial ultramarino, a través del Galeón de Manila, permitió que la sociedad novohispana disfrutara de bienes traídos del lejano oriente, en especial los biombos y los rodaestrados.

La presencia de estos muebles en los hogares reflejaba la posición económica de la familia que los poseía, y también constituían un símbolo de prestigio y de estatus social, ya que era difícil adquirirlos, no solo por su valor monetario sino también porque eran objetos de importación.

La sociedad de Pachuca del siglo XVII fue compleja, y las diferencias se reflejaron en el contenido de los ajuares domésticos. Es interesante observar que en todos los grupos citados se encuentran camas, biombos, rodaestrados y espejos, que en sí eran símbolos de riqueza, sin embargo, las familias con mayores recursos poseían objetos usados de más valor (en los últimos grupos encontramos sobre todo camas y colgaduras de cama con precios excesivamente altos, aunque en el primer grupo observamos una cama en cien pesos), mientras que las familias menos favorecidas económicamente obtenían objetos nuevos aunque de menor valor.

Resalta la importancia que los primeros grupos, aquellos cuyas familias dotaron a sus hijas con menos recursos, daban a la adquisición de una mayor cantidad de muebles de cama y de sala, con respecto a aquellas familias que ofrecieron dotes más altas. En este sentido, podemos suponer que los grupos de la élite no requerían hacer tanta ostentación de riqueza a través de la obtención de bienes de lujo debido a que ya la poseían, y que basaban su estatus social y poder en otro tipo de bienes, como propiedades (haciendas, minas, casas), dinero y esclavos.

Existían otros muebles al interior de las casas que constituyeron también símbolos de estatus y de prestigio, como escritorios, escribanías, mesas, sillas, cajas y baúles, cuyo estudio es tema de otro artículo.

Por último, hay que reconocer que las mujeres contribuyeron de manera importante al desarrollo socioeconómico de la población de Pachuca durante el siglo XVII a través de la dote, sobre todo con la adquisición de bienes de importación, sin embargo, en el ámbito público no se les permitió participar ni destacar. Esta limitante las obligó a reproducir los valores dentro del ambiente que les era propio: el familiar, y a apropiarse de lo íntimo y lo privado que les ofrecía la sala y la recámara al interior del espacio doméstico.

\section{Referencias}

AHPJEH. Archivo Histórico del Poder Judicial del Estado de Hidalgo.

“Anónima Descripción de las Minas de Pachuca". (1993). En Juan Manuel Menes Llaguno. Monografia de la ciudad de Pachuca. Colección Lo nuestro... México: Instituto Hidalguense de la Cultura, Gobierno del Estado de Hidalgo. pp. 42-45.

Brading, D. A. (1985). Mineros y comerciantes en el México Borbónico (1763-1810). México: Fondo de Cultura Económica.

Cubillo, G. (1991). Los dominios de la plata: el precio del auge, el peso del poder. Empresarios y trabajadores en las minas de Pachuca y Zimapán, 1552-1620. México: Instituto Nacional de Antropología e Historia, Colección Divulgación.

Curiel, G. (1992). "Consideraciones sobre el comercio de obras suntuarias en la Nueva España de los siglos XVII y XVIII”. En José Guadalupe Victoria et al. Regionalización en el arte. Teoría y praxis. México: Universidad Nacional Autónoma de México. pp. 127-160.

Curiel, G. (2005). "Ajuares domésticos. Los rituales de lo cotidiano", en Historia de la vida cotidiana en México, dirigida por Pilar Gonzalbo Aizpuru. Tomo II. La ciudad barroca, coordinado por Antonio Rubial García. México: El Colegio de México, Fondo de Cultura Económica. pp. 81-108.

Fernández, J. (1984, reimpresión). Catálogo de Construcciones Religiosas del Estado de Hidalgo, Vol. II. México: Secretaría de Hacienda y Crédito Público, Dirección General de Bienes Nacionales, Talleres Gráficos de la Nación.

Gonzalbo A., P. (1992). "Hacia una historia de la vida privada en la Nueva España”. Historia Mexicana XLII:2. México: El Colegio de México. pp. 353-377.

Gonzalbo A., P. (1996). "Las cargas del matrimonio. Dotes y vida familiar en la Nueva España”, en Pilar Gonzalbo Aizpuru y Cecilia Rabell Romero (coordinadoras). Familia y vida privada en la historia de Iberoamérica. México: El Colegio de México. Instituto de Investigaciones Sociales, Universidad Nacional Autónoma de México. pp. 207-226.

Gonzalbo A., P. (2007). "Afectos e intereses en los matrimonios en la ciudad de México a fines de la Colonia". Historia Mexicana LVI:4 México: El Colegio de México. pp. 1117-1161.

Lavrín, A. (1985). "Investigación sobre la mujer de la Colonia en México. Siglos XVI y XVII”, en Asunción Lavrín (compiladora). Las mujeres 
latino-americanas. Perspectivas Históricas. México: Fondo de Cultura Económica. pp. 33-73.

Lorenzo M., C. (2015). Arte suntuario en los ajuares domésticos. La dote matrimonial en Pachuca, siglo XVII. México: UAEH.

Menes, J. M. (1993). "Anónima Descripción de las Minas de Pachuca". Monografia de la ciudad de Pachuca. México: Gobierno del Estado de Hidalgo.

Mijares, I. (2005). "El abasto urbano: caminos y bastimentos", en Historia de la vida cotidiana en México, dirigida por Pilar Gonzalbo Aizpuru. Tomo II. La ciudad barroca, coordinado por Antonio Rubial García. México: El Colegio de México, Fondo de Cultura Económica. pp. $109-140$.

Martínez del Río, M. J. (1982). "Artes menores: artes industriales". Historia del Arte Mexicano. Tomo 8. Arte Colonial IV. México: SEPSalvat. pp. 1172-1189.

Pérez H., P. (1992). Comercio y mercados en América Latina Colonial. Madrid: Editorial Mapfre.

Rubial G., Antonio. (1994). "La sociedad novohispana de la ciudad de México". En Isabel Tovar de Arechederra y Magdalena Mas (compilación). La muy noble y leal ciudad de México II. Ensayos sobre la ciudad de México. México: Departamento del Distrito Federal, Consejo Nacional para la Cultura y las Artes, Universidad Iberoamericana, A. C. pp. 67-84. 